\title{
Analysis of the Critical Discourse and Adversaries
}

\author{
Manna Dey ${ }^{1, *}$ [deymanna113@gmail.com] \\ ${ }^{1}$ North South University
}

$\begin{array}{llll}\text { Received: } 18.10 .2021 & \bullet & \text { Accepted: 20.12.2021 } & \text { • }\end{array}$

\begin{abstract}
Discourse analysis is a branch of study that encompasses a variety of varied, primarily qualitative methods to the investigation of the interactions that exist between language in use and the social environment. Language is often viewed by researchers in the subject as a sort of social practice that has an impact on the social world and vice versa. Many contemporary kinds of discourse analysis have been overtly or indirectly informed by Michel Foucault's theories of power, knowledge, and discourse, which are discussed below. As a result of Foucault's work, there has been an increased interest in investigating the role that language plays in the formation and maintenance of certain knowledge and the maintenance of inequitable power relations. In order to undertake discourse analyses, human geographers often draw on one of three major schools of discourse analysis: Foucauldian discourse analysis (FDA), critical discourse analysis (CDA), or Gramscian techniques. There are several theoretical and methodological distinctions between these approaches. While different approaches have different strengths and weaknesses, they all provide researchers with an effective means of investigating and exposing semiotic features of power relations in specific sociospatial contexts. While there are no set procedures for these techniques, researchers have recognized certain essential investigative strategies that can be used to inform the performance of any type of discourse analysis project. These strategies are included below. A brief history of Critical Discourse Analysis is offered, along with a full examination of the numerous criticisms levied at CDA and its practitioners over the previous two decades, both by scholars working within the "critical" paradigm and by other critical critics. Reader response and integration of contextual aspects are discussed, as well as a range of objections directed at the underlying premises and analytical technique. Additionally, there is discussion of contentious issues, such as the negative focus of much CDA work and CDA's developing standing as a "intellectual orthodoxy" They highlight the major criticisms that have emerged from this overview and provide some ways to overcome these shortcomings.
\end{abstract}

Keywords: Analysis of the Critical Discourse, Research methods, Linguistics corpus research, Critique of the paradigm, Contextualization.

\section{Introduction}

Critical Discourse Analysis is now extensively regarded as a topic within the humanities and social sciences, and the abbreviation "CDA" is frequently used to refer to a recognized approach to language research employed by a variety of different organizations and disciplines. Others say critical discourse analysis is on the verge of becoming a "an intellectual orthodoxy" (Billig, 2002, p.44), an institutionalized discipline with its own paradigm, canon, and conventionalized assumptions, as well as a form of power structure. When it comes to thinking and exploring, CDA

\footnotetext{
*Corresponding Author: deymanna113@gmail.com
} 
has established itself as a legitimate paradigm, among the other intellectually credible paradigms. It is remarkable that even scholars who identify as critical discourse analysts have reservations about CDA's status as a critical paradigm. The validity of CDA is considered by some as a contradiction to the critical activity itself, or as a threat to the reflexivity inherent in its critical agenda, as a result of its increased respectability alongside other traditional disciplines" (Billig 2002, p.36). However, certain CDA-affiliated scholars assert that there is no unanimity among themselves (Fairclough \& Wodak 2017, p. 271; Chouliaraki \& Fairclough, 2017; Van Dijk 2003, p.352). Another group is disappointed that so much of the work produced in the discipline of critical discourse analysis has been negative, and urges critical scholars to devote more emphasis in the future to positive or potentially transformative applications of discourse (Martin 2004, pp.183-4; Luke 2002, pp.106-7). Additionally, linguists and others outside of CDA have been a constant source of well-informed critique, pointing out oddities within the field of CDA. Criticism has exposed weaknesses in epistemology and theoretical framework, such as theory's instrumentalization and inability to give an objective stance for research, to mention a few. They have however, criticized the prevalent linguistic methodology and underlying theories of language and communication, as well as the way CDA researchers may fail to adequately integrate context and audience into their conceptual approach, resulting in naively knowable assumptions about discourse and social reproduction. Before digging more into the many critiques thrown at Critical Discourse Analysis and its practitioners from both within and outside its disciplinary limits, a brief assessment of the rise of Critical Discourse Analysis is important to identify its main concepts and intellectual underpinnings. The following is a brief history of Critical Discourse Analysis's rise.

\section{Critical discourse analysis: a brief summary}

\subsection{Defining critical discourse analysis}

Although this paper's start refers to CDA as a "program" it does so as a distinct entity, as does much of the literature on the issue (Wodak, 2011, p.50). As a disclaimer, many academics, particularly those working within this paradigm, consider that referring to CDA as a monolithic, homogeneous entity is inaccurate. Critical discourse analysis will be defined in this study as a tendency or movement that is both recognizable from the "outside" and self-aware, in the sense that its adherents think they are operating within the "critical" paradigm of discourse analysis (Wodak 2011, p. 50). Distinguish between the British approaches of Fairclough (2019, 2018), Fowler (2019), Chouliaraki, and Fairclough (2017), the so-called "sociocognitive model" of critical discourse analysis as exemplified by Van Dijk (2019) and his group, the Viennan "discourse historical school" led by Wodak, and the American "critical discourse analysis movement" (Wodak et al. 2019; Wodak 2017, 2007). Along with the French school of CDA, which dates all the way back to Pêcheux (2018). Wodak (2011) distinguishes the Duisburg school (Jäger, 2017), which focuses on media language through Foucault's lens, from the Maas (2018) approach, which examines how contradictions in society are encoded in texts and how readers are induced to collude in ideological digression. Due to space limits, this article will be unable to analyze each of these schools in detail, but we will attempt to emphasize the criticisms thrown against certain groups of analysts and to highlight the exceptions.

For the sake of this study, we will use the term critical discourse analysis (CDA) to refer to a huge body of theory and research created by specialists who identify as critical discourse analysts in some way. This reduces the need to constantly confine the scope of reference to "many critical discourse analysts" or "the majority of people working within the CDA paradigm" If necessary, distinct sub- 
groups or writers within the CDA tradition will be identified, due to the danger of over-generalization when using the term CDA as an umbrella term. As a self-aware movement with a clear mission, CDA is rich with definitions of who it is and what it does. To "To explain existing conventions as the result of power relations and power struggle" (Fairclough, 2018, p.2), or to "to answer questions about the relationships between language and society" (Rogers, 2005, p.365), depending on the researcher's position. A more or less political interest in the workings of ideology and power in society, as well as a special interest in the ways in which language reveals, perpetuates, and contributes to these workings, are two of the most prevalent characteristics of Critical Discourse Analysis. As a result, all of the more specific formulations highlight the relationship between language (text, discourse) and power. (political struggle, inequality, dominance).

"When it comes to language and power, the CDA takes a unique position. More precisely, this research analyzes the more or less explicit connections between struggle and conflict (Weiss \& Wodak, 2002, p. 12).

"CDA involves a principled and transparent diverting back and forth between microanalysis of texts using various tools of linguistic, semiotic, and literary analysis, and the macroanalysis of social formations, institutions, and relations of power that these writings index and construct" (Luke 2002,p.100).

"Politics," "power," and "ideology," not to mention "critical, discourse, and analysis," all present a number of issues that will be examined in the following section, which will briefly review CDA's intellectual background.

\subsection{Precursors of the intellectuality}

An effort to integrate Halliday's Systemic Functional Linguistics into a broader social perspective that could include political problems of power and control began to take shape in the late $2017 \mathrm{~s}$, resulting in the formation of the Critical Discourse Analysis movement. Several early works, including "Language as Ideology" by Hodge and Kress (2017) and "Language and Control" by Fowler, et al (2018), laid the groundwork for CDA's current position (1979). Critical Discourse Analysis, which appears to have been invented by Fairclough in a 2019 book, became popular thanks to the publication of 'Language and Power' (Fairclough 2019, p.739). Fairclough's (2018) formalized adverbial "Critical Discourse Analysis" published in 2017, helped to establish the phrase. It would appear, however, that "the critical study" as one critic put it, has "coalesced into a uniformity that could be identified as a critical study" because the inclusion of "the" as definite article in its subtitle indicates that it is a critical study (Billig 2002p. 35). Even if this is a small exaggeration, the fact remains that Fairclough's term has taken root throughout the country. Despite the fact that there are numerous publications on CDA, Fairclough's two books are undoubtedly the most well-known, and they are frequently mentioned across a wide range of disciplines (Rogers et al. 2005, p. 365, 371). From the standpoint of linguistics, the CDA is a product of the anti-structural linguistics movement that took place in the United States throughout the 1960s and 2017s, according to the author. CDA was a linguistic theory that was similar to Systemic Functional Linguistics, pragmatics, conversation analysis, and ethnographic research in that it took the social roles of language seriously. While many SFL researchers embrace descriptive linguistics and structuralist reasoning, CDA rejects these ideas as being fundamental to the field. Another significant difference was that, in contrast to other approaches, the CDA concentrated on power and assumed that the social ties depicted in language were part of a larger pattern characterized by unequal power relations, as opposed to other methods. In this context, language is not a goal in and of itself, but rather an indication of what is happening in a much wider network. 
CDA's politicized concern with society can be traced back to Marxist or neo-Marxist authors, and in particular to Adorno, Marcuse, and Horkheimer of the Frankfurt School, according to most CDA histories. There was a lot of interest in how Marxist theory could provide light on twentieth-century changes in capitalism, which was a major focus of the Frankfurt School. As a result, they focused their attention on changes in capitalism that, in their opinion, resulted in the perpetuation of oppressive structures through ideological techniques of resistance. Marxist thinkers distinguished themselves from other sociologists of the period because of their normative orientation. However, Marxist social scientists argued that their role was to evaluate and prescribe rather than observe and analyze, as would be the case in a natural science setting. Consequently, they adopted a "critical" stance because they believed they had the authority to evaluate what was going on in society and because they believed they were in possession of the required standards by which to do so. Summary: This particular set of philosophers claimed to have access to knowledge about not only how society is currently structured, but also how society should be structured in the future.

The Frankfurt School and the majority of critical discourse analysts do not have any direct connections, with the obvious exception of the discourse-historical school (see below), despite the fact that they use the same terminology and have a common background in Marxist approaches to late capitalism (Chouliaraki and Fairclough 2017). However, the Frankfurt School is not the only source of inspiration for the Center for Digital Art. Several social sciences departments adopted a "critical" approach during the 1960s and 2017s. In addition to Bourdieu (2019), from whom it gained the notions of habitus, symbolic capital, and systems of meaning, the theory has received contributions from other authors, including Habermas, who emphasized the role of communication in contemporary society. The impact of these theorists on CDA was limited to their studies of society and their insights into the function of ideology in the construction and maintenance of social institutions, despite the fact that they were interested in language. Critical linguists, on the other hand, have been burdened with the duty of finding and exploring these occurrences in their actual linguistic forms.

Attempts have been made to situate CDA within a larger language heritage at various points in time. Taking this a step further, Luke (2002, p. 97) situates CDA within what he describes to as a "distinguished if incomplete history of attempts at a normative political linguistics," which, according to Luke, can be traced all the way back to Voloshinov and Bakhtin. When taken together, Luke (2002) contends that these tendencies create a "viable counter-tradition in linguistics" (Luke 2002, p. 97) that rejects liberal or neoliberal views of the individual and society in the social sciences generally, and linguistics specifically. It is his contention that the Center for Democratic Analysis is not a formal school of thought, but rather a collection of positions that broadly advocate for an examination of the role of language in society from an explicitly political perspective, with a particular emphasis on how dominant groups' interests are advanced through discourse. Many CDA specialists believe that it is essential to distinguish their own work from that of "non-critical" linguists or discourse analysts by insisting that their analyses go beyond a simple description and interpretation of language's role in society to an explanation of how and why language works as it does (Fairclough 2018). As defined by Fairclough (2019, p. 9), "critical" means "revealing hidden connections and causes" which includes decoding the operations of id eology, because the discursive patterns of ideology disguise the power conflicts that exist in the social reality.

Foucault's post-structuralism has had a substantial influence on CDA, however it is not completely compatible with the other influences discussed above. Against structuralist conceptions of society such as Marxism, Foucault argued that there are regular, observable linkages between structures inside systems and that human beings can gain knowledge of these relationships by observation and 
experimentation. According to Foucault's critique of structuralism, the transitory nature of social concepts, the fluid nature of power relations, and the critical role played by language in constructing social connections (Foucault 2017, p. 25-28) were all highlighted. For Foucault, speech is a dynamic process that alternates between reflecting on and creating social worlds for the numerous agents who use it or are positioned by it, depending on the context.

Orders of discourse are the discursive activities of a society or organization that are interconnected and intertwined with one another. According to Foucault, access to meaning, on the other hand, is impossible (Foucault 2018, p. 54). Instead, he concentrates on evaluating the conditions of existence for meaning and the principles of meaning generation, which are both important topics. Instead of focusing on interpretation and hermeneutical goals, he chooses to concentrate on discursive actions in a world where all discourses are relative and always shifting. Advocates of CDA, who focus the majority of their research on discourse phenomena, have embraced the priority accorded to language by Foucault in its most fundamental form. As defined by Fairclough and Wodak (2017, p. 258), discourse is significant because it is ideological in nature, defining and conditioning society and culture, building and maintaining power relations, all while remaining strangely transparent or invisible to those who utilize it. The relativist message of Foucault's theory, on the other hand, is frequently overlooked by CDA practitioners in favor of a more fixed or normative approach to the interpretation of social phenomena.

\section{Critical Discourse Analysis Criticism}

\subsection{Rebuttal to underlying principles}

Persons working in the field of CDA, as we have seen, are rarely unwilling to defend their own political position, their own view that research must be "critical" in all of the above-mentioned criteria, or to defend their own political perspective. Furthermore, the diverse character of CDA's intellectual heritage makes it more difficult for researchers to determine the precise reason for a particular attitude or interpretation. Detractors have accused CDA of acting arbitrarily, guided by personal whim rather than well-founded academic principle, while others have attempted to identify and explain the unique philosophical and sociological foundations of CDA, concluding that they are illogical and erroneous in their conclusions.

Fairclough and others, according to Hammersley (2017, p. 237-248), have proclaimed the necessity of a critical approach as if it were self-evident and uncontroversial, a charge that Fairclough and others have denied. Beginning with the discrediting of orthodox Marxist theory, Hammersley contends that the vast majority of Marxist theories have been dismissed as mechanical, unfounded, and unhelpful for comprehending current society by philosophers, historians, and economists. Next, he turns his attention to the Frankfurt School, which, as previously said, is often seen as giving direct antecedents for the Conceptual Developmental Approach (CDA). Because the alterations Adorno and Hochheimer made to Marxist theory were exceedingly radical, he contends that the Frankfurt school does not provide a sound foundation for CDA's critical mission. These alterations extended far beyond economic concerns to themes of alienation, reason, and human nature, according to him. Those who held this view believed that alienation was caused by "the distortion of Western rationality, particularly the latter's pursuit of control over the natural world, including human nature" (Hammersley 2017, p. 242), which raises a slew of unresolved questions about the fundamental logic of scientific inquiry. Furthermore, the sort of critique provided by Adorno, for example, appears to undermine the logic for favoring one actor over another and raises doubts about the possibility of gaining freedom in the first place. The Frankfurt school may have been interested in understanding 
social change and may have provided a detailed critique of orthodox Marxism, but according to Hammersley, the Frankfurt school does not provide an effective conceptual foundation for "critical" research of the type conducted by critical discourse analysts. The fact that numerous studies support Hammersley's central contention that CDA's philosophical foundations are taken for granted, as if they were unproblematic (2017, p. 244), does not rule out the possibility of a more thoroughly grounded approach; nor does the inherent difficulty of an approach based on a critique of Western rationalism rule out the possibility of such an approach. Hammersley's most stinging criticism, in the end, is directed at the grandiose claims made by CDA practitioners that they can provide a comprehensive understanding of society and how it works that is "superior" to other perspectives exactly because it is undertaken in a spirit of self-reflexive critique (2017, p. 244-5). Given the fact that this assumption underlies a significant chunk of its claim to legitimacy, CDA specialists must pay close attention to this component of their work's epistemological base as well as the ramifications of this assumption for their methodology and research.

It's worth emphasizing at this point that the term "critical" has served a singular role throughout the history of the Frankfurt School. In the United States of America, where the term "Marxist" was thought objectionable, members of the Frankfurt School were deported, and the term "Marxist" was coined (Scholem 2018, p. 210). As previously stated, the term "critical" in this first sense refers to the ability to evaluate society through the lens of a specific ideology, in this case Marxism, as previously indicated. Indeed, the term "critical" has a long and illustrious history that dates all the way back to Kant, who used it to denote that his analysis was built on rational a priori principles "without the aid of experience," as opposed to the blind dogmatism of his forefathers (Kant 1781, p. 3; Bilig 2002, p. 37). While a number of approaches in the social sciences have adopted the term "critical" in the post-Frankfurt era, none is more prominent than critical psychology. Critical psychology, like many other approaches, claims intellectual descent from the Frankfurt school (despite the fact that many of its approaches appear to have little in common with the work of these theorists), and it operates on the assumption that all knowledge is based on experience (Gergen 2018, p. 11-20). It is associated with Paulo Freire's "critical pedagogy" in education, which reiterates the purpose of resisting dominance and releasing oppressed people via the development of critical consciousness. As a result, the term "critical" is used widely across fields to denote "critical of the status quo" or "critical of liberal humanist perspectives," and is often used to express a commitment to social change rather than to criticize a particular viewpoint.

Furthermore, the term "critical" has at least two additional alternative definitions, which further adds to the uncertainty. On the one hand, the Frankfurt School theorists recognized that their work was "critical" in another sense, in that it offered a critique of what they believed to be orthodox Marxism's authoritarian positivism. On the other hand, they recognized that their work was "critical" in another sense, in that it offered a critique of what they believed to be orthodox Marxism's authoritarian positivism (Shaw 2019, p. 165). Instead, they argued that it was necessary to challenge widely held beliefs and to develop new, more comprehensive, and comprehensive understandings of capitalism's development that went way beyond traditional Marxist perspectives. Furthermore, they should be self-critical, with the goal of holding their own work to rigorous intellectual standards as part of the process. Most CDA approaches, on the other hand, tend to naively assume their own left-wing political perspective, which is a component of the Frankfurt school's "critical" heritage that does not play a large role. The discourse historical approach (Wodak 2017; Reisigl and Wodak 2009, pp. 8689), which distinguishes three dimensions of critique, namely textual, socio-diagnostic, and prospective/retrospective, and advocates for critical self-reflection at various stages of the analytical process, is a notable exception to this general tendency. Alternatively, Gloy (2017) and the so-called 
Oldenburg school (Bredehöft 2018, p. 4; Bluhme 2000, pp. 10-13) advocate for a position that acknowledges analysts' participation in the discourses they study while insisting that scholars must always reveal their own perspectives and demonstrate their grounding in order to give their opinions.

Alternatively, in addition to the multiple interpretations of the adjective "critical" in this context, we must also consider the following consideration: Traditional liberal education in most Englishspeaking nations emphasizes the importance of "be critical," which means thinking for oneself rather than accepting what one reads at face value - an intellectual skill that is not dependent on any particular ideological affiliation. On the surface, it appears as though the word "criticalpolysemy " may have contributed to certain misunderstandings about the job of the discourse analyst and what, if any, political stance she should adopt. The term "critical" is used by many scholars to describe themselves in general because their education encouraged them to be critical; others define "critical" to mean being critical of society from a neo-Marxist perspective; and still others define themselves as "critical" to mean taking a critical stance toward specific neo-Marxist positions. Consequently, meanings become entangled, resulting in a reduction in clarity and intellectual precision. Given the definitional challenges at the heart of the CDA project, it's not surprising that the project's consistency is sometimes questioned on occasion.

At the same time, as previously mentioned, there is a substantial contradiction between the Marxist and post-structuralist parts of CDA's ideological beginnings, which is a source of contention. The post-structuralist and post-modern movements, in contrast to Marxists, reject totalizing metanarratives as being erroneous and exploitative. At the same time, it is difficult to justify employing a particular meta-narrative to comprehend observed facts in the postmodern intellectual landscape at the level of individual political decisions in the postmodern intellectual landscape. At one time, Foucault, for example, notoriously refused to make value judgments about the discourses he was researching. Similarly (Foucault 2017). It has been proposed under a postmodern context that one simply "chooses" certain ideas or viewpoints through an existential self-definition process generally referred to as decisionism, rather than the other way around (Habermas 1976; Macintyre 2018). The fragmentation of the moral and intellectual order makes it difficult to find consistent foundations for rational politics or reasoned political discourse. As a result, there is no practical chance of increasing human emancipation.

Given these seemingly contradictory scenarios, Hammersley wonders if it would be more appropriate to classify CDA researchers as post-structuralists, as individuals who have chosen a particular stance by will rather than through extensive deliberation on the basis of the facts and issues presented to them. It follows, he contends (2017, p. 242-245), that CDA's political stance should not be preferred over any other, and that CDA's declarations of "interpretive power" and"emancipatory force" should be treated as ordinary assumptions that can be accepted or rejected depending on the reader's point of view.

A wide range of ramifications flow from CDA's status as a method of approach. In addition, as Hammersley points out, if the political perspective upon which CDA is founded is found to be unfounded and mainly the consequence of decisionism, this will be at odds with the strong claims CDA makes for itself and its actions. Given that one of the central tenets of critical inquiry is that research should be explicitly designed to serve political functions (such as exposing inequality and injustice) rather than the more conventional purpose of research (which is to observe and interpret phenomena), then there must be a sound rationale for this position to be taken into consideration. If the explanation is essentially a matter of personal preference, there is no reason for the reader to see this form of research as being important or worthwhile. 
Before engaging on the interpretation and explanation of social phenomena, CDA scholars are often extremely forthright about their personal political opinions and beliefs in general. Even though Fairclough believes in principle that critical research does not have to be left-wing and that rightwing forms of critical deliberation are entirely feasible, he regularly stresses his traditional Left leanings (Fairclough 2017, p. 52). There are two points to be made in this regard. There are two implications of this: first, if this is true, then Fairclough's and others' interpretations must be highly controversial, because any left-wing interpretation might be criticized equally from the right, or from any other political dimension that may exist. As a result, it is possible to see the CDA's entire scholarly effort as being heavily impacted by political choice rather by scientific criteria, which may be deemed to serve a supporting role. First and foremost, the fact that members of the Coalition for Democratic Accountability (CDA) frequently demonstrate their commitment to transparency and candor by identifying their political affiliations does not absolve them of the need to conduct objective research. Bourdieu has made reference to the fragile nature of many of these assertions, as well as the significance that self-definitions play in academic power struggles, in his writings on the subject (2019b, p. 308). To be sure, writers writing within various types of post-modern frameworks are frequently tempted by the prospect of avoiding difficult epistemological issues by taking an explicit position from the outset. For example, post-modern approaches to feminism (Harding 1112), where the typical rationale is that a feminist perspective is necessary in order to rebalance a patriarchal-dominated system, are particularly prominent. Whether or not this answers the problems of post-epistemological modernism, such gambits do not give the author carte blanche to alter the facts or interpret the data in any way he or she sees fit in order to achieve a specific political goal. Given the amazing diversity of CDA's conceptual antecedents, it is surprising that there is so little disagreement within CDA circles about their relevance, if not their compatibility, with current CDA thinking. C.D.A. continues to be equivocal about its precise preferences for a certain social theory, as Slembrouck (2017: 40-41) observes. The intellectual basis of the United States appears to have extended rather than shrunk through time, according to historical trends. So while Fairclough (2018) is heavily influenced by Neo-Marxism and a Gramscian view of hegemony, in which naturalised "common sense" serves as the vehicle for ideology and text is used as a site of struggle, Chouliaraki and Fairclough (2017) construct a research agenda that is engaged in an ongoing dialogue with late modernity, feminism, and postmodernism ten years later. Consequently, CDA is able to draw on a vast and sometimes contradictory panorama of sociological ideas, ranging from Marx to Gramsci, Horkheimer, and Giddens, and also on an enormous diversity of approaches to language and communication, including Bakhtin, Foucault, Habermas, and Halliday, seemingly without ever feeling the need to justify this eclecticism. Moreover, according to Weiss and Wodak (2002), the theories or constructs derived from various philosophical or sociological thinkers are merely tools to be used as appropriate in any given situation, similar to how linguistic approaches are viewed as tools to be used as appropriate in any given situation: "one can speak of a theoretical synthesis." (...)

This includes Foucault's discursive formations and Bourdieu's habitus, as well as Halliday and Bernstein's register and code, among other concepts (2002, p. 7). Because of this, critics have remarked that CDA frequently acts at the interface between an array of ideas and an universe of speech, utilizing the one to explain and justify the other but not explicitly confronting or addressing either of these on its own terms (Slembrouck 2017). For practical purposes, this could lead to a situation in which philosophical, political, and sociological arguments are not fully developed in terms that are acceptable to specialists in these fields, and in which the foundations for language analysis are not securely built in a manner that is recognized by linguists It is critical to return to the core question of whether the diverse range of theories adopted by distinct CDA researchers is a 
strength or a weakness in light of what has been said thus far. According to a number of authors, the fact that CDA researchers' findings may be linked to a variety of philosophical and social concepts indicates the field's breadth and depth. In their opinion, it would be regrettable if CDA's potential were to be restricted to a specific interpretative school or to a certain philosophy of language or society. A large number of discourse analysts argue that this openness is a virtue rather than a flaw in the discourse (Chouliaraki and Fairclough 2017; Weiss and Wodak 2002). Fairclough (2018, p. 10) argued that the critical enterprise was "not simply another approach to language study (...) but an alternative orientation to language study." even during the early years of CDA. CDA appears to be a massive church that can accommodate large groups of people.

The CDA, on the other hand, has expressed dissatisfaction with the situation. As Fowler (2017, pp. 8-12) put it more bluntly, "it appears as though anything qualifies as discourse analysis (...) There is a danger of competing and uncontrolled methodologies derived from a scattering of disparate social science models." he concluded. In such an eclectic environment, the consequences of action are selfevident: lack of coherence, haphazard mixing of incompatible notions, haphazard application of procedural rules, and so on. Apart from the issue of academic rigor, there are also unresolved issues about the definition and understanding of one's own subject.

\subsection{Textual description: Methodological criticisms}

The book "Language and Power" (2018) by Fairclough establishes a framework for text analysis that is based on standard discourse analysis approaches and bears a debt to Halliday and Systemic Functional Linguistics. Examples include Fowler (2017), Chouliaraki and Fairclough (2017), and Chouliaraki and Fairclough (2017), all of whom openly claim Halliday's framework as the intellectual foundation for their analyses. There are three levels of language activity, as described by the well-known three-tiered framework: the ideational (the construction and representation of experience in reality), the relational (the enactment of social relationships), and the textual (the expressing of social relations) (production of texts). Language connects meanings to their spoken and written expressions, allowing them to be communicated more effectively. Both meanings and expressions are intricately tied to events that take place outside of language, most notably social life, to the point where "the social is built into the grammatical tissue of language" as one scholar put it (Chouliaraki and Fairclough 2017, p. 140). As stated by these writers, by attentively investigating specific instances of language - such as texts or encounters - scholars can determine the social relations that these instances of language reflect, configure, or repeat, as well as the social context in which these ties are formed. The authors argue that any such investigation should be unbiased and rigorous, and that it should draw on a variety of linguistic research procedures, ranging from qualitative approaches ideal for conversation analysis to quantitative approaches found in corpus linguistics.

So it appears that the language framework and analytical method used by CDA experts are not subject to debate. Nonetheless, some of the most vehement criticism leveled about CDA has been focused at one particular area: Many CDA studies in practice suffer from major methodological problems, despite the fact that the theory may be sound and the approach appears to be promising in certain cases.

The primary problem does not appear to be a lack of understanding of the need of rigor in this situation. The author of a 2019 assessment of twenty papers published in Discourse and Society believes that if the authors had paid more attention to textual and intertextual characteristics, their analyses would have been more persuasive. His review, on the other hand, is symptomatic in that, 
rather than condemning this lack of rigor, he expresses regret that an opportunity to support specific conclusions was missed, to the extent that "the entire exercise (...) appears to be a communitybuilding exercise rather than a search for enhanced understanding" (Verschueren 2017, p. 67). A similar lack of scholarly rigor can be found in the application of linguistic approach in a slew of publications that claim to use critical discourse analysis as their methodology. A review of 40 articles using CDA in the field of education published up to 2003 by Rogers et al. (2005, p. 385) found that one-quarter of the articles did not make any reference to language theory, while the remainder made references to CDA and SFL, as well as discourse theory, many in general terms and only a few in specific detail. While critical analysts frequently claim to be using techniques adequate for communication ethnography, other researchers have observed that they frequently fail to portray scenarios or the procedures by which such material was acquired in a manner acceptable to ethnographers, despite their assertions (Blommaert 2017, p. 14-17).

At the level of data gathering and subsequent analysis, it is commonly known that there are methodological errors present in the data collection process. In this section, I will focus on the way by which CDA researchers obtain their data, rather than the data itself. In the section that follows, I will pay my attention to the question of interpretation, as well as the associated issue of reader response, which will be discussed further.

Widdowson has been one of the most outspoken critics of the CDA in this area for quite some time $(2017,2005)$. In a study of three sample studies published in the 2019s, Widdowson focuses on the ad hoc nature of some CDA research, which he finds to be problematic. According to his interpretation, Fowler $(2017$, p. 8$)$ stated that critical linguists get a lot of mileage out of a small number of linguistic concepts such as transitivity and nominalisation, which he interprets as meaning that "analysis is not the systematic application of a theoretical model, but a rather less rigorous operation, in effect a kind of ad hoc bricolage that draws from a variety of sources" (Widdowson 2017, p. 136). As Widdowson continues, Fowler points out that other analytical approaches (such as categorical analysis (CA), schema theory, and so on) could be utilized just as successfully if they were integrated into the "critical" model. He believes that any approach will suffice as long as the intended results are achieved. He also believes that any way will suffice.

When it comes to CDA's appraisals of numerous key works, Widdowson goes over the material in great detail in order to establish what he believes to be the method's lack of objectivity in its application.

There are certain conclusions that can be drawn about the ideology of the text by focusing on specific lexical items or grammatical qualities (passives, nominalizations, etc.). He does, however, question if this is legal. He believes that these characteristics were chosen more or less arbitrarily, and that the researcher intuitively believes that they will create conclusions with ideological importance, it is probable that the remainder of the text, which may include contradictory facts, will be overlooked. As Widdowson points out, it is not impossible that certain grammatical parts (such as passives, for example) do genuinely possess a "higher ideological valency" (2017, p. 148). His contention is that critical discourse analysts have not yet proven that this is the case, or even addressed the question of how this may be demonstrated. He believes that corpus methodology, with its larger samples and more rigorous approaches, may be able to help to the resolution of the problem. The conclusions of such studies would be less likely to be affected by the "randomness" and susceptibility to bias that Widdowson attributes to Fowler (2017), Fairclough (2017), and van Dijk (2017), as well as other researchers (2017). (2017). Note at this point that Widdowson has been unable to explain 
scientifically that such "randomness" exists in the data selection process, which serves to undercut his thesis in certain ways.

CDA academics have been motivated by the fundamental premise that discourse analysts should attempt to apply objective criteria and rigorous scientific procedures (for example, by engaging with larger samples of text or by utilizing corpus tools) to their work, which has guided much of their current work (see below). It is significantly more important to apply Widdowson's assessment to the early years of the CDA, namely to British authors such as Fowler and Fairclough, rather than the latter.

Toolan (2017) and Stubbs (2017), for example, address the issue of potential analytical bias by stating that CDA, at least in its early phases, usually failed to approach texts in a systematic manner. Stubbs argues in favor of a comparative approach based on broad, representative samples of the population. As part of this, he addresses the question of method by digging into what many discourse analysts refer to as the "description" level of discourse analysis. As stated in Fairclough's (2018) fundamental definition, description comprises determining the experiential, relational, and expressive meanings of the words and grammatical structures in a text, in addition to the textual structures and interactional patterns that can be observed.

For this reason, many discourse analysts would rather concentrate on only one of these traits, or a subset of one of these qualities, such as the use of passive voice or nominalisation (Fowler et al. 1979; Fowler 2019; Fairclough 2019a, 2019b). In the opinion of Stubbs, the conclusions reached by discourse analysts on the basis of such analyses are unsupportable, either because the method is typically entirely impressionistic or because the sample of texts is small and acquired on the fly. According to Fairclough's (2017) study, public language (academic writing, political speech) is becoming less formal. Stubbs cites this study as evidence of this trend. This is Fairclough's central issue, according to Stubbs, because he provides no quantitative evidence for it, and particularly no quantitative evidence that the degree of informality is increasing over time. Indeed, while Fairclough's arguments appear to be persuasive, his methods of gathering evidence are not explained, and his conclusions are not presented in a form that allows them to be questioned by others. Indeed, when a large number of CDA studies are carefully examined, it becomes evident that most of the argument is based on a small number of essential phrases (for example, the word "enterprise" in Fairclough 2017). In spite of this, as Stubbs points out, "registers are very rarely defined by individual features, but rather by clusters of associated features that have a greater than chance of co-occurrence" (2017, p. 3).

The primary thrust of Stubbs' argument holds true, despite the fact that it is impossible to make broad generalizations about CDA methodologies. This is because some critical analysts, particularly during the 1980s and 2019s, paid insufficient attention to methodological consistency and provided little, if any justification for their own approaches. While their work may contain genuine intuitions, it does not adhere to the standards of rigor associated with academic research.

In his article, Stubbs points out that "there is scant discussion of whether it is sufficient to limit analysis to brief fragments of data, how data should be sampled, and whether the sample is representative" of the population $(2017$, p. 7$)$. Also possible is that pieces will be portrayed as representative without any explanation as to how this representativeness was achieved.

However, while Stubbs is not anti-CDA, the core of his argument is that the procedures employed are insufficient to justify the apparently gained results, with the result that the interpretations and explanations must be regarded as doubtful. It is undeniable that his knowledge in corpus linguistics 
has affected his manifesto for a methodologically sound form of discourse analysis, but it is nonetheless instructive:

- "To put it another way, the text analysis must be lot more thorough. Individual texts must be compared to one another as well as to corpus data in order to be considered comparative. Before generating broad generalizations about regular language use, researchers need collect a far broader variety of data than is often used in discrete data fragments. Additionally, because variations in language use are determined by clusters of co-occurring elements, a far greater range of linguistic attributes must be investigated; this entails the use of quantitative and probabilistic text and corpus analysis methods." 10 (Stubbs 2017; p. 10)

To be sure, many discourse analysts had already recognized the need for a more systematic technique that could be used across larger, more representative samples of discussion by the time Stubbs published his book (cf. Wodak et al. 2019; van Dijk 2017; Hoey 2017, p. 154; Wodak 2017). The incorporation of corpus technique into CDA has been increasingly popular (Mautner 2017, p. 122; Partington 2003, p. 12; Partington 2006, p. 267; Baker et al. 2008, p. 277-283; Partington 2006, p. 264-264). Following his initial criticism of CDA methodologies, Fairclough went on to conduct a study of "new Labour" language that was based on massive quantities of empirical data and incorporated the use of corpus linguistic tools in order to obtain a more representative portrait of the movement (Fairclough 2000, p. 17).

However, to be fair to Fairclough and the CDA as a whole, Stubbs's background in corpus linguistics predisposes him to favor studies involving large samples of text, particularly contrastive studies designed to highlight the distinctive features of different genres or registers through the use of statistical methods, which Fairclough and the CDA generally oppose. However, it should be noted that this is not the only approach of analyzing linguistic data. In the case of textual analysis, it would be a mistake to disregard qualitative techniques because they obviously give a genuine alternative to quantitative research, which also has a lot of flaws and inconsistencies. Similar to this, it would be inappropriate to dismiss CDA conclusions simply because they were not gathered in this manner. When it comes to analyzing specific sorts of discourse, such as that of a single politician or political party, a close, qualitative analysis of a limited sample of text may be the only choice available.

Verschueren (2017, p. 60) takes a somewhat different approach, pointing out the lack of detailed consideration of language and interaction in some CDA analyses (for example, Verschueren criticizes Chouliaraki and Fairclough's 2017 textual analysis, which Verschueren finds to be lacking). Verschueren emphasizes on the tendency for essential elements of the text to be excluded because they do not fit into the interpretive framework. The author, after conducting a survey of numerous cases where this selective proclivity was demonstrated, comes to the conclusion that many alleged discoveries are "the product of conviction rather than the result of a careful step-by-step analysis that reflexively questions its own observations and conclusions" (2017, p. 65).

Verschueren admits the validity of Fairclough's three-stage analysis (description, interpretation, and explanation, as discussed above), but he takes issue with the analyst's journey from the first level (description) to the second level (interpretation and explanation) of the analysis (interpretation, that is, locating the text as discourse). Fairclough is reliant upon

He refers to the following as "members' assets" (2018, p. 167):

In this stage of the approach, the analyst's genuine self-consciousness is what distinguishes her from the persons she is analyzing. A participant interpreter fulfills the same functions as a participant analyst; however, unlike the participant interpreter, the analyst is more concerned with explaining her actions." " 
In his argument, Verschueren claims that by including the concept of "members' resources," Fairclough has virtually abandoned the topic of empirical proof. Due to the fact that all interpretations (including those of participants and onlookers) are founded on the same working knowledge of language and culture, the analyst's interpretation is only as valid as any other interpretation (including those of participants and onlookers). As Slembrouck has pointed out, members' resources are conceptually influenced and warped by social power relations, and there is no guarantee that they will not be duplicated or manipulated intellectually as a result of this (2017, p. 39).

Once the analyst has reached the level of interpretation, Fairclough believes that he or she will have no difficulty moving on to the last step of explanation. In contrast, because interpretation is dependant on members' resources, the only different between a participant and an analyst, for example, at the level of explanation is that the analyst has the ability to draw on social theory to interpret what he or she has observed. Verschueren believes that it is at this point that CDA's claims to possess interpretative insights begin to crumble. "the only real criterion for explanation is a sound social theory." he says. There is no mention of the empirical dimension, which is essential for connecting facts and theories" (Verschueren 2017, p. 69). A key point, according to some critics (Slembrouck 2017), is that maintaining a separation between researcher and researched only on the basis of access to social theory is not suitable.

Verschueren provides a detailed analysis of how, in his opinion, Fairclough (2018) fails to adequately handle the empirical component - that is, fails to give a rigorous and systematic analysis of the text - in a comprehensive fashion. The crux of Fairclough's argument is that he analyzes isolated texts without placing them in the social and intertextual contexts in which they are generally considered to be situated. Using the example of news reporting, Fairclough believes that a linguistic trait such as nominalisation is being exploited to hide issues of agency and avoid assigning blame. But when placed in the context of a specific article or scenario, as well as the ongoing reporting on a specific subject across numerous issues of the same newspaper, readers may be able to distinguish clearly who is responsible. According to Verschueren's core point, Fairclough fails to contextualize the text, removing it from its context and failing to pay attention to areas of the text that do not match expectations, leading in erroneous findings.

Verschueren (2017, pp. 60-79) investigates a similar event that occurs when Fairclough attempts to evaluate verbal interaction in a group setting. By analyzing two "traditional" and two "alternative" doctor-patient contacts in Fairclough's (2019, pp. 50-52) case study, Verschueren shows that Fairclough's conclusions are unfounded (Verschueren 2017, pp. 70-71). It is his contention that Fairclough starts with the imposition of a contrastive framework that causes the data to be distorted and ignores items that do not match the predetermined scheme. There are two major flaws in the methodology, according to Verschueren: first, general aspects of context are ignored (such as whether or not the patient has a specific problem or whether or not the doctor and patient are acquainted); and second, form-function relationships are treated as stable, which is not acceptable in pragmatic terms. To begin, Fairclough assumes that the first doctor exerts control over the interaction through questioning, but she does not address the possibility that, in addition to questioning, the second doctor exerts control more subtly by providing minimal responses and waiting for the patient to continue - or that the second doctor may simply be uninterested in the patient or wishes to appear non-committal.

A more systematic, objective, and disciplined approach to qualitative analysis of ideology in texts is advocated by Verschueren, who outlines specific principles for doing so, including the need for 
horizontal and vertical text exploration as well as sensitivity to pragmatic issues in the relationship between form and function, as well as the concern that the meanings should elucidate the ideology (see Verschueren 2011). As the history of the CDA shows, practitioners frequently make only the bare minimum of concessions to methodological constraints and do not always explain their own research methodology in an open and transparent manner (Rogers et al. 2005). The major shortcoming of approaches such as Fairclough's (2018) is that they place a high value on the researcher and his or her interpretive and explanatory abilities, and, as Verschueren (2017, pp. 6077) points out, they provide no explanation for how or why specific aspects of the text are deemed to have one meaning or another - the researcher's judgment is sufficient, a question of interpretation is sufficient, and a question of interpretation is sufficient (Fairclough 2018, p. 167; Verschueren 2017, p. 68). Fairclough's (2018, p. 167) assertion that "it is only truly self-consciousness that distinguishes the analyst from the participants she is analysing" is singled out for criticism because multiple readings are possible and the purpose of analysis is to provide something more solid than a subjective impression, through the application of a rigorous method that is theoretically grounded, is singled out for criticism. However, as Verschueren (2017, p. 68-69) notes, the methodological and interpretive concerns raised by Fairclough's following investigations are crucial and remain unanswered adequately. In the words of Chouliaraki and Fairclough (2017, p. 67), CDA "advocate a particular interpretation of a text, though it may advocate a particular explanation." of texts. This, according to Verschueren, eliminates any argument that the analyst holds privileged understanding, thereby eliminating the need for rigorous study and "understanding" of the material... (Verschueren 2017, p. 69). Textual analysis is characterized by a disdain for the epistemological and hermeneutic components, as well as an overemphasis on the theoretical dimension of explanation. Verschueren ends by pointing out Fairclough's (2018, p. 167) distinction between the analyst as reader (who has the same "member's resources" as any other reader) and the analyst as explainer (who has a different "member's resources" than any other explainer) (the analyst is superior to other readers because he or she can draw on social theory).

In other words, the only valid criterion for explanation is the existence of a sufficient social theory of the world. In the absence of any reference of the empirical dimension, which is essential in order to connect facts and theory, As a result of the theory's preconceived nature, it should come as no surprise that its "findings" are predictable and that a disconnect between textual analysis and conclusions emerges - even among those who, like myself, agree on significant portions of the theory - as soon as the question of evidence is raised. Texts are only changed into transmitters of information that has already been determined to be correct. It is preferred that positioning take precedence over interpretation rather than the traditional progression from description to explanation to placement with interpretation at the heart of every stage of the research. 69 The year is 2017, and Verschueren is the author of the book.

Because of this, the question of interpretation is intimately linked to the issue of reader response, which is inevitably linked to the issue of reader response. Because the question of how discourse analysts may or should interpret text is intrinsically related to the question of how readers absorb text, the two issues are hopelessly linked.

These challenges arise when analyzing quantitative language data, but they become even more relevant when the research is conducted solely on a qualitative basis. The following part will go into additional detail about the issues that have been encountered. 


\subsection{The reader's relationship with the text: Acknowledgement and response}

Perhaps the most severe criticism directed at the CDA project has been leveled at the level of textual interpretation itself. Critical discourse analysts have been accused of a sort of naive language determinism, which is at the extreme end of the spectrum. (Kress, 2017, p. 25) has given the following explanation, which Widdowson (2017) calls attention to:

- I would argue that this collection of semiotic traits and representational resources suggests and implies a specific disposition, a specific habitus, and hence contributes to the creation of a specific kind of subjectivity over time.

- "the interpretive ingenuity associated with literary criticism" says Widdowson, is analogous to the method used by the analysts (2017, p. 136). Consequently, he claims, discourse analysts have accidentally returned to a "transmission view of meaning" in which "significance is always and only a reflex of linguistic signification" (2017, p. 142).

On the basis of this premise, a large number of opponents have taken aim at CDA's interpretation of the interaction between texts and readers. However, not in its original form, in which the possibilities of a particular language code determine the habitual thought processes of language users, but in an expanded form, in which discourses similarly produce, condition, and constrain thought processes (Widdowson 2017, p. 139), several authors have identified what they refer to as "the well-known Whorfian notion of linguistic determinism" It is self-evident that there is a significant relationship between people's perceptions of reality and the language they use. Nonetheless, it is equally obvious in a worldwide society that people are exposed to a range of discourses and learn to navigate them, ignoring some, accepting others, and rejecting others. Although this is a self-evident truth, much CDA research is undertaken under the assumption that there is a simple, one-to-one relationship between the text and its reader, or between the discourse and its recipient. If we acknowledge from the outset that some discourses are more powerful or influential than others, and concentrate our attention on those that are particularly likely to have an impact on a large audience, or try to figure out the factors that influence such an impact, this would be more subtle and realistic.

The circularity of the argument is one of the most significant flaws of this strategy. Despite the fact that it is possible to demonstrate that language usage influences cognition, this argument is weakened if language usage is the only evidence for cognition. As a result, we must proceed with extreme caution when deducing information about the mind from language or vice versa. Language both represents and influences cognitive processes, thus we must exercise extreme caution when deducing information about the mind from language or vice versa. According to Stubbs (2017), if researchers desire to make assumptions about what individuals think based on what they read or hear, they should acquire non-linguistic proof for their views or do behavioral research on the individuals in question. "if we lack independent evidence and instead infer beliefs from language use, the theory is circular." he writes on page 6 of his 2017 book. Stubbs's approach has a number of flaws, including the fact that it is unclear how one would precisely deduce people's thoughts and views without relying on language, and that it is far from straightforward to connect discourses to non-linguistic data such as observable behavior without using language. In spite of this, his criticism is fair, because it is irrational to assume that language has a one-way impact on the mind, and it is methodologically erroneous to operate as if the existence of such an influence is uncontested.

To address the problem from a slightly different perspective, some CDA researchers have spent considerable time investigating the mechanisms through which they believe texts influence persons in order to support their own hermeneutic methodologies. A theory of representation and transformation developed by Kress $(2019$, p. 91-117) is posited as the process via which discourses affect or alter people's perceptions of reality. Sebastien Halliday's concept of representation is the 
foundation for his theory, which relates to the method by which reality is ideationally represented. The notion of transformation is not taken directly from Halliday, but rather appears to be conceptually distantly related to Chomski's concept of metamorphosis, according to the evidence. One of the primary issues is the attention placed on how images are altered, maybe as a result of ideological impact on the subject.

There is also a certain circularity in this, as Widdowson $(2017$, p. 138) points out, because representations are by definition encoded versions of reality, and it is difficult to know precisely how we are to distinguish between representations and transformations in this context. The theory of language change, or discourse change, appears to be presented here, albeit it is not entirely clear how one can distinguish what has changed from what. Interestingly, this has some similarities to the topic of the difficulty of identifying creative language as a divergence ("Abweichung") from normal language in Coseriu's book (1980, p. 51). It is necessary to deviate from anything in order to be considered a deviation; yet, who determines what constitutes a departure? Furthermore, it may be feasible to "deviate" in a variety of different ways from the original plan. Furthermore, although transformation is presented as a binary choice, there is no way to judge which side is accurate or even whether a binary choice exists at all, or whether there is a continuum of possible outcomes to consider. Several forms of grammatical construction are considered neutral or "non-transformed" by Hodge and Kress (2017), which means that while they are representational, they do not have any unique representational value - they are "innocent representations of reality." Others, on the other hand, are transformed, and altered sentences "always involve some form of suppression or distortion" according to the American Psychological Association (Hodge and Kress 2017, p. 35).

In reality, according to a large body of research undertaken in the 2019s, it appears that change takes place when grammatically "less simple" structures, such as the passive, are used to transfer information. But none of these academics addresses the question of whether the passive is necessarily ideological or whether the passive is actually "less simple" than the corresponding active version of the same sentence. Widdowson takes issue with Kress's concept of metamorphosis in a number of different ways.

Under the first place, he reminds us that in a Chomskian model, all word strings are modified and potentially transformable, which means that there are no neutral or innocent sentences that are not transformed.

This paradigm does not allow for the differentiation of changed sentences from non-transformed sentences. Secondly, Widdowson draws a connection between Kress's claim that changed sentences are more complicated and the derivational theory of complexity, which was developed in the 1960s and proposed that structural complexity was reflected by psychological complexity, with the resulting difficulty in processing as a result. As a result, it was believed that passive sentences required more effort to decipher because they are inherently more intricate than active sentence structures. Similarly to the previous hypothesis, this one proposes that some structures are more intricate than others, and that this has an impact on the reader/receptor. In the field of language processing, however, the evidence that supports this view is in direct conflict with this notion. During experiments to test the processing speed or ease of various linguistic structures, it was observed that individuals were unable to distinguish between their knowledge of the language and the context in which it was presented. According to Olson and Filby (1972), when events or inquiries were categorized in terms of the actor, active propositions were processed more quickly, but passive propositions were processed more quickly when they were coded in terms of the action's recipient. According to them, "comprehension of a passive sentence does not always imply recovery of the 
passive's base structure equivalent to the active sentence, or the base structure equivalent to the passive's base structure equivalent to the active sentence." "The S-V-O structure is commonly assumed to underpin (...) the meaning of a sentence" $(1972$, p. 379). Other trials (Wales and Grieve 2017 , p. 327-332) demonstrated that individuals found it remarkably easy to comprehend complex structures when they were placed in a given context; in other words, they tended to make pragmatic interpretations rather than engaging in linguistic analysis of complex structures.

CDA publications from more recent years place a lesser emphasis on the concept of transformation. Although the underlying concept is rarely mentioned (see, for example, Schröder 2002; Kuo \& Nakamura 2005; Stenvall 2007; and see also Billig (2008) for a detailed discussion of the various ways in which passives and nominalisation have been deemed "mystificatory"), passives are frequently accused of depriving certain groups of agency or concealing agency, among other things. Finally, as Widdowson (pp. 138-141) points out, the entire concept of representation versus transformation, of innocent language versus ideological manipulation, appears to be in direct conflict with another CDA premise, that all language is ideological and that nothing can be considered neutral. As a result, the distinction between representation and transformation becomes increasingly blurred, leaving the analyst with no firm ground on which to stand.

As a result, how can the analyst comprehend texts and determine the text's impact on the reader? They are acutely aware of the challenges that this scenario presents and are quick to point out that ideological interpretations cannot be drawn solely from literary qualities and that textual study should be combined with examination of production and consumption activities (Fairclough 2017). However, they provide no evidence for such behaviors and usually rely on a transmission model of hermeneutics, in which language structures "convey" or "construct" meaning, which is considered to have been swallowed in its totality by the reader, as opposed to a construction model.

Even CDA specialists acknowledge that ideological meanings are frequently ambiguous and must be extracted with difficulty by the discourse analyst; however, they appear to be communicated easily to the reader and capable of gently exerting an ideological impact on him or her, according to CDA specialists. The content of the text is therefore completely concealed, delicately enmeshed in syntactic structures and vocabulary choices, yet that same meaning, unreadable to the analyst, is communicated to readers, having an ideological impact on them in the process. The difficulty of interpreting reader response is further complicated by problems with context access, which are discussed in greater depth in other sections of this work. This is because inadequate consideration of context tends to obscure how actual participants in any scenario understand and interpret it. Because his or her "members' resources" include access to social theory, the researcher risks "risks losing sight of whatever spontaneously productive 'hermeneutics' already exist in the lifeworlds" (Slembrouck 2017, p. 42), i.e., what the participants actually believe is taking place when he or she privileges their own position.

The topics of reader reaction, analytical approach, and hermeneutic possibilities have all been thoroughly addressed in literary studies throughout the years. In their criticism of CDA, critics such as Widdowson accuse it of subordinating analysis to interpretation, of discovering in the text what they set out to find (Widdowson 2017, p. 149), they usually refer to an analogous problem in literary criticism: the problem of the author's voice. As a kind of political poetics, CDA raises the same questions regarding the textual rationale for war as other forms of political poetry. As a result, it is beneficial to do a quick examination of how this subject has been dealt in literary studies in order to establish fascinating parallels between CDA and other topics. 
In their respective books, Stubbs and Widdowson acknowledge that the hermeneutics challenge in CDA is reminiscent of arguments about literary criticism and reader reaction that took place in the 1960s and 2017s. However, their claim that the issues are sufficiently analogous to be addressed in the same manner is open to question. Overall, arguments over reader response originated as an implicit reaction to prior theories of literature that placed a premium on the author or the content and form of a literary work, as well as in explicit reaction to New Criticism and formalist ideas that eliminated the role of the reader. Those who advocated for reader-response techniques were concerned with the notion of the reader as an active agent who, via interpretation, completes the meaning of a literary work, which some skeptics argued would lead to relativism or even chaos. As Stubbs points out, Fish $(1980$, p. 341, 347), in an attempt to answer the problem of readers' varied responses, argues that the book loses meaning when it is not considered in the context of a set of cultural beliefs about what it means and how it should be interpreted. In the "interpretive community," these assumptions are reflected by criteria for reading a specific book in a certain way and developing norms for what is and is not permitted in reading a given book in a particular way.

While the fundamental issue addressed by reader response theory is similar to the issue of interpretation addressed by CDA, it is vital to recognize and underline a number of important differences. The first thing to note is that responses to literary works are fundamentally different from responses to conventional informational or instrumental texts. They are also more nuanced and multidimensional.

It is more useful to use approaches to audience reception that are common in media studies rather than reader response theory, which is more commonly applied to works of art. These approaches to audience reception are useful for determining what people understand from a particular text or for detecting deviant readings that occur in particular social settings. If we accept CDA's assertion that obscure patterns and hidden meanings in discourse eventually exert ideological influence, then the notion that a "interpretive community" would be useful in determining the meaning of discourse is obviously suspect: the community may be positioned in support of the hegemony, or it may contain a variety of different interpretive communities, among other possibilities. More to the point, when we talk about the type of text that is usually examined by CDA, we are not referring to the way a text is "interpreted," as is the case in literary studies, but rather to the way a text is accepted, used, acted upon, modified, parodied, or even ignored.

In this sense, the concept of the "discourse community" which is more familiar to applied linguists, or the concept of the "community of practice" which is more familiar to educationalists, are more useful tools for understanding how discourse operates in specific social situations (Kent 2019, p. 425-445; Lave and Wenger 2019, p. 22-23). For example, according to Bhatia (2002, p. 6), extensive descriptions of a group's communication activities "may unravel many of the mysteries of how members of various discourse communities function to accomplish institutional and disciplinary goals and justify their discursive practices." Recent investigations (Sarangi and Roberts 2017; Candlin et al. 2000) have found that Moreover, there is a substantial body of research in media studies that indicates that the influence of texts and broadcast material on subjects is much less oneway and much more complex than might be assumed (Abercrombie 2017; Nightingale 2017; Reese et al. 2003), due to the fact that people bring a diverse range of prior knowledge and interpretive techniques with them. Such studies would be integrated with discourse analysis research in an ideal world to identify how media, institutions, and other texts "work" in their respective natural surroundings. 
Despite this, the subject of obtaining evidence of a text's influence on the reader or listener is rarely discussed in CDA research studies. A clear theory of audience effects and audience reaction to substantiate CDA's assumptions about the influence of discourses on human beings is lacking in the field of communication studies and communication ethnography, and in general, CDA practitioners are unaware of the bodies of research in media studies and communication ethnography.

\subsection{The CDA and its context: Is it excessive or insufficient?}

Discourse is socially embedded, according to one of CDA's central ideas: it is both socially formed and contributes to the building and perpetuation (or "reproduction") of social structures and linkages. Fairclough and Wodak (2017) state that CDA is committed to social justice, with the stated goal of raising readers' awareness about "how language contributes to the domination of some people by others, because consciousness is the first step toward emancipation" (how language contributes to the domination of some people by others) (Fairclough 2018: 1).

In the context of social interaction, language is a complex phenomenon because it both creates and disrupts social interactions. Furthermore, diverse linguistic media are inextricably linked to one another as well as non-linguistic media, resulting in an intricate web of intertextuality and multimodality. The fact that one criticism raised with CDA is that the most overtly social components of discourse, namely the social contexts in which speech happens, are usually disregarded is notable.

The difficulties associated with CDA's claims to provide an interpretation of social reality originate in the fields of conversation analysis, communication ethnography, and pragmatics, to name a few areas of expertise. In essence, these strategies differ from CDA in that they emphasize the importance of a bottom-up approach rather than a top-down approach (Peace 2003: 164). Ethnographic research and conversation analysis are both characterized by meticulous data gathering through the use of recordings and thorough transcripts, and both fields are committed to the premise that interpretations should emerge from the facts. When it comes to language, pragmatics is concerned with the roles that language performs in real-world situations, with the subtle relationships that exist between form and social function, and with the rigorous investigation of individual examples of language use. Despite the fact that CDA professionals frequently advocate for "There is an observable trend toward "constant movement back and forth between theory and data" (Meyer 2017, p. 27), or at the very least toward "constant movement back and forth between theory and data" (Reisigl and Wodak 2017, p. 33; Rogers et al. 2005, p. 382; van Dijk 2006, p. 359; Wodak 2007, p. 203), or at the very least toward "constant movement back and forth between theory and data" (Reisig

Both conversation analysis and conversation data analysis are interested in naturally occurring speech, interaction, and text, and both think that discourse is intrinsically tied to context and social structures, as evidenced by their respective fields of study. However, the field of conversation analysis emerged from a different intellectual lineage, in part as a response to advances in mainstream sociological theory and practice.

However, while generalizations run the risk of oversimplifying, it is generally accepted that conversation analysts concentrate their research on the contact itself and are unwilling to include what transpired before or after the contact in their sphere of interest. It has been referred to as the study of "micro interactions" at various points throughout history (Rogers 2005, p. 378). CDA, on the other hand, tends to broaden its scope to encompass the macro-environment, the function of interaction in social connections, institutional power systems, and other factors of importance.

Some critics argue that CDA does not necessarily pay close attention to the linguistic aspects of interactions, but rather jumps too quickly to the macro context, making statements about how macro 
relations might be mapped onto micro interactions, rather than the other way around (Widdowson 2017). The current context, which affects the type of interaction that takes place in social situations, is usually overlooked or completely ignored (cf. Verschueren 2011). To put it another way, according to Verschueren (2017, p. 60), the lack of methodological rigor and, more specifically, the omission of context meant that the CDA was responsible for "subjecting the media, as well as other institutions, to a circus trial, playing fast and loose with observable facts in order to support preconceived claims." particularly in its early years.

In the late 2019s, contact with CDA researchers who were experimenting with conversation analysis tools sparked a heated debate about the use of such techniques. Schegloff argues that context should be supplied only insofar as it causes concern for the participants during the interaction, to outline his main arguments for doing so. How is it possible to identify only one contextual component that is analytically meaningful in a particular interaction, considering the virtually infinite number of contextual factors that could influence a given interaction? If a man and a woman meet, for example, it is possible that gender issues will come up, but it is also possible that gender issues will not come up at all since the participants are not concerned with them on this specific occasion When faced with this situation, would it be appropriate for a gender researcher to impose an analytical framework on the interaction?

The goal of conversation analysis, according to Schegloff, should be to gain a better understanding of how ordinary interaction takes place, how identities are negotiated, and how persons speak in a range of situations. It is the optimal analytic method to achieve this goal if one can determine the orientations given by the participants as well as their function in the interaction. Even after it has been established that certain aspects of the context are significant, the analyst must proceed with caution in determining precisely what they might mean in the specific situation at hand, rather than jumping to conclusions about meta-categories such as "gender" or "power." in general. Potter (2017, p. 31) describes the process as follows: "Participants construct, deal with, and are directed toward the context, which is referred to as "contextualization." " Participants' characteristics such as their ethnic origin, the characteristics of the environment, and other 'ethnographic' details are not regarded as distinct components" Because researchers in this school do not see social structures as places of interaction, but rather as evidence of how social phenomena are formed or constituted, as Potter points out, the conventional barrier between micro- and macroanalysis is becoming increasingly blurred.

While it is self-evident that researchers cannot approach data in the real world without prior preconceptions, Schegloff proposes that scholars seek to anchor their study in the interaction itself, concentrating on what is significant to the participants, rather than the facts. "this is a useful constraint on analysis, constraining work to the indigenous preoccupations of the everyday world that are grasped, and acting as a buffer against the possibility of academic and theoretical imperialism, which imposes intellectuals' preoccupations on a world without regard for their indigenous resonance." he writes in 2017.

While Schegloff's criticisms are well-founded, their relevance to the CDA is up for discussion. Defending a specific technique, such as conversation analysis or ethnographic studies in which no external categories are imposed on the study topic, does not rule out the validity of other approaches that do impose external categories on the study topic, as exemplified by other approaches such as qualitative research. Researchers in the field of conversation analysis employ a variety of techniques, including those associated with conversation analysis, and there is no reason why they should be required to adopt a set of assumptions or principles simply because they employ elements of a 
particular technique in their research. In his book, Van Dijk (2017, p. 460), he characterizes the point of contention as contextualisation, stating that it is permissible for CDA to research text and context independently, as well as to investigate how contextual components influence or are impacted by text. The extent to which certain external categories are relevant to the interaction must therefore be determined by individual researchers, and CDA researchers are not constrained by typical academic rules.

From a slightly different perspective, one could accuse CDA of failing to take context into consideration because it frequently analyzes decontextualized samples of language, in which texts or portions of texts are analyzed without regard for the context in which they were produced, disseminated, or consumed. Other scholars, particularly communication ethnographers, have emphasized the importance of taking context into consideration, arguing that texts are entangled in social contexts and cannot be understood without a thorough understanding of the web of social interactions within which they were produced or developed. Fortunately, in fields such as education, many more recent studies have combined CDA techniques with specific types of ethnographic methodology, acquiring qualitative data from a number of sources such as fieldnotes and other forms of observation, documents, interviews, and focus groups (Rogers et al. 2005). There is less emphasis on context in the subject of media studies, which is closely related to CDA in many ways, partially because it is more difficult to define context, identify and monitor readers or viewers, obtain precise descriptions of how media texts are formed, and so on. In contrast to other media specialists, CDA practitioners frequently have more naive notions of how media texts function than hermeneutics and reception scholars, for whom audience responses or production processes are key components of the research operation.

Considering the ideological direction of CDA, it is reasonable to assume that the flaws stated above are a result of that orientation: Given society's preoccupation with power, CDA proponents may be eager to identify specific aspects of the text that appear to reflect their underlying thesis and to move quickly through the stages of interpretation and explanation rather than devoting time to laborious examination of the language itself or to exploring the immediate contextual surroundings, as is the case with traditional interpretation. This, according to some authors (Verschueren 2017), can even result in circular arguments and results that are effectively a confirmation of the obvious. CDA studies of the mass media in the 1980s tended to reveal that the media, for example, served to maintain the ideological status quo, which is hardly surprising given the social theory to which the vast majority of CDA scholars adhere. It is possible that researchers will overlook what makes particular instances of language use unique or distinctive in favor of macro-patterns that validate the researchers' initial idea because ideological categories will outnumber contextual variants due to the prevalence of ideological categories. Even when the case is stated, the conclusion is ultimately inconsequential. As Verschueren points out, "presenting predictable patterns as 'findings' diverts attention away from more interesting questions about how they contribute to the generation of meaning" As a result, by jumping from what might be called "symptoms" (recognizably distinguishable features of a specific phenomenon) to the macro-context, we learn a variety of things.

One distinguishing trait of certain CDA research that is based on macrostructures is a penchant for generalization and stereotyping, which is a characteristic of certain CDA research. For example, Blommaert (2017: 15) observes that critical discourse analysts frequently begin with preconceived notions about the primary actors in a given context, such as "politicians are manipulators" or "the media are ideology-producing machines." They also frequently begin with stereotyped sociotheoretical constructs, such as business, institutions, and "traditional medicine." Among the contextual components he offers are three that he believes are overlooked by traditional CDA: 
resources, text trajectories, and data histories, all of which he believes are overlooked by conventional CDA.

He defines resources as a collection of sociolinguistic strategies and communicative talents that people bring to a given situation, which can be summarized as follows: "the significance of resources is rooted in the close relationship between language and a broader economy of symbols and status in societies" according to the author (Blommaert 2017, p. 23). Inasmuch as linguistic resources are intricately tied to power distribution, language provides a direct route to the heart of social organization. They are commonly overlooked in CDA research because they are not inherent in individual texts, but rather must be understood in relation to social institutions and the way language functions in a given culture. A text trajectory is the progression of discourse from one setting to another, such that an interview becomes a set of notes, then a case study, and potentially even an entire part of a review article, according to the term "text trajectories" Yet another problem is that many CDA academics choose to concentrate on single instances or genres rather than following discourses' "natural history" across a variety of contexts and text types, which can lead to an erroneous or at best a partial picture of the situation. There are notable exceptions, particularly within the Viennese school of discourse analysis, where a broader perspective has been adopted in order to cover a representative range of text types over an extended period of time (see, for example, Wodak 2017; Reisigl 2007,p. 34), but this is a highly complex undertaking that not all discourse analysts are capable of undertaking. Finally, "data history" refers to the actual data collection procedure, which in ethnographic research must be meticulously documented in order to account for observer effects or likely observer bias, among other considerations. The researcher's stance on the specific political issues at hand should be described in this section, rather than a general classification such as "leftwing" or "radical," which are notoriously inaccurate and open to diverse interpretations.

The author concludes by pointing out that many of the challenges associated with CDA are due to the importance placed on text in the CDA tradition: Despite the fact that CDA scholars claim to be examining society through text, they typically end up only interpreting the content they read. In this case, if the tables are turned and discourse is considered a social phenomenon occurring within a framework that includes language, social connections (including power structures), and power structures, it may be possible to move closer to the goal of "explaining society through the privileged window of discourse" (2017, p. 28).

However, it is safe to conclude that the most frequently chosen CDA position favors interpretation and explanation in terms of specific categories of interest to the researcher, regardless of the specifics of the case. The term "context" in the context of CDA often refers to the macro-context: the power dynamics that operate throughout society. This typically results in the omission or dismissal of aspects of the current micro-context, which can be detrimental. This ideologically motivated approach stands in stark contrast to the notions that underpin numerous closely related analytical fields of language studies that are not ideologically motivated.

\subsection{CDA as a fundamentally negative compound}

Several CDA practitioners have stated that their enterprise is fundamentally political in nature, with the goal of transforming the world and empowering the oppressed: "CDA is fundamentally political in nature, with its practitioners acting on the world in order to transform it, and thus contributing to the creation of a world free of gender, color, age, and social class," they have stated (CaldasCoulthard and Coulthard -ix 2017). They do recognize, however, that this goal is rarely achieved: they say 
Initiatives in critical language have remained precisely that: criticisms of texts and the social practices implied or realized by those texts, exposing inequitable, demeaning, and poisonous systems of affairs [...] Providing that critical language projects develop suitable and plausible theories for this area, they will be able to make the leap from critical reading to analysis, and from deconstructive to generative activity. CL or CDA have not explicitly offered (productive) descriptions of other types of social structure or of alternative sorts of social subjects in their works. (15) and (16) (Kress 2017).

Given CDA's beliefs about the structure of society and its preoccupation with uncovering ideological manipulation that creates and maintains power disparities through speech, it should come as no surprise that language researchers at this school prefer to deconstruct rather than construct their findings.... In an article advocating for more positive work in discourse analysis, Martin draws particular attention to the negative aspects of CDA, identifying CDA as part of "a pathological disjunction in twentieth-century social sciences and humanities research that systematically elides the study of social processes that make the world a better place in favor of critique of processes that disempower." It is this sort of negative deconstruction, which he refers to as "CDA realis," that he considers to be the most important face of CDA since it is primarily concerned with "exposing language and its attendant semiosis in the service of power" (2004: 179). While he acknowledges that CDA includes a secondary dimension devoted to constructive social action, which he refers to as "CDA irrealis," he also points out that this dimension has been rarely applied in practice. "we need a complementary focus on community, one that considers how people come together and carve out space for themselves in the world - in ways that redistribute power without necessarily fighting it" Martin argues (2004: 186). It is the goal of this "Positive Discourse Analysis" to explore how positive transformation occurs, such as how indigenous peoples overcome their colonial history or how sexism is eliminated and new gender relationships arise. It is through the study of such phenomena that we can obtain a greater knowledge of how positive changes occur and, as a result, be better prepared to encourage change in the future.

Martin, for example, recounts the Australian government's inquiry into forced adoption of indigenous children, which is particularly innovative within the genre of the bureaucratic report in that it focuses a strong emphasis on the victims' perspectives on the matter. The importance of narrative and biographical literature in drawing people's attention to injustice and influencing public opinion is also discussed by the author. Throughout the book, Martin expresses his discontent with the orthodoxies of the CDA movement, stating that "proposing a ten-year moratorium on deconstructive CDA in order to get some constructive PDA off the ground" would be "going too far" (2004, p. 199).

The CDA must go beyond ideological critique, according to Luke (2002, p. 98), in order to realize its full potential. He calls this "the productive use of power" or, in Freirean terms, "emancipatory discourse." and it must do so in order to do so. "if CDA is to be a normative form of social science and political action, it must be capable of demonstrating both what "should be" and what is problematic" writes Martin (2002, p. 105). And if it doesn't, he argues, the CDA will be stuck in a deterministic negative paradigm in which all media are instruments of central ideological control and CDA practitioners play the "enlightening" role of the Gramscian intellectual, raising awareness and mobilizing the populace against hegemony, rather than the other way around. Due to the fact that this would be reductive (not to mention that it would presuppose certain highly dubious assumptions about both the nature of the audience and how the media works), Luke proposes that a new, more optimistic CDA should focus on minority discourses and diasporic voices, emerging counter-discourses, and reinterpretations of mainstream discourses by diverse groups. We would miss an opportunity if we remained stuck in dialectical analyses of economic disparity and political 
oppression in the face of globalisation. We would also miss out on important opportunities if we failed to come to terms with new cultural configurations, new modes of negotiating identity, new counter-discourses, and voices of resistance. The abandonment of outdated dichotomies will be required to meet this challenge on a theoretical level, and the collection of evidence and the development of appropriate methods for investigating the new discourses and new media that characterize life in the twenty-first century will be required on a methodological level in order to meet this challenge.

\subsection{CDA as a form of intellectual dogma}

Critical Discourse Analysis (CDA) was developed as a ground-breaking method of language analysis in the early twentieth century. Despite the fact that the term "critical" is ambiguous, if not meaningless, there is no doubt that what unites those who refer to their work as CDA is a belief in their ability to step back from their data and apply critical analysis techniques - both to the texts or interactions themselves and to the society in which they take place. The critique, as previously indicated, is essentially political in character, with a particular emphasis on issues of power and injustice. A bold and unique approach to language study, CDA appeared to be one in which existing orthodoxies could be challenged in the name of social commitment.

While the CDA has gained traction over the past twenty years, as is typical with successful new movements of any kind, there has been a gradual push toward institutionalization and acceptance over the course of that time. According to some authors, CDA experts are actively seeking to establish CDA as a unique technique or school in and of itself, rather than merely a subset of other methods or schools (Verschueren 2017, p. 67). CDA practitioners are urged to create greater selfawareness and self-criticism, according to Billig (2002), who documents this transition and speculates on what it might mean to be a "revolutionary" discipline.

Billings (2002) pays particular emphasis to the use of the acronym "CDA" in his narrative, which he says has given the abbreviation the status of an academic "brand. The rhetorical strategy of an academic is, in his opinion, to promote their work as a part of a spectrum that has been endorsed or assured by a particular theoretical perspective or viewpoint. The "branding" of this approach is typically performed through the use of acronyms and abbreviations only (Billig mentions SIT, Social Identity Theory, in sociology as an example, but one may equally think of SFL, Semantic Field Theory, in linguistics). Specifically, according to Billig (2002, p. 42), this form of labeling enables academics to "market" their ideas "as branded and identifiable intellectual products in today's academic world" a practice that is becoming increasingly common in a fiercely competitive aca demic world that is becoming increasingly dominated by market rules and regulations. Having established a strong presence in universities, with its own journals and a significant number of academics who subscribe to its central tenets, CDA has become an integral part of the academic power structure, and aspiring scholars who accept its principles and methodological assumptions can become members of the organization. According to academic authority, CDA is currently on a level playing field with other branches of language research (the ability to publish books or articles, to make appointments, and to gain advancement). Some argue that a critical paradigm has been intellectually produced - a critical orthodoxy that is rigid, dogmatic, and exclusive in the same way that earlier orthodoxies have been in some respects.

Also of note is Billig's emphasis on the importance of the term "critical" in CDA's understanding of itself as well as its marketing efforts. He reviews the history of the term "critical," from Kant to Piaget and Popper, not to mention the Frankfurt School (see above), and suggests that the term's primary function has typically been to insist on the objectivity or intellectual credibility of one's own 
enterprise while undermining the "uncritical," "non-critical," or "acritica." enterprise. As a result of CDA's insistence that academic work address the critique of power in society, as well as the distinction it draws between itself and disciplines or paradigms whose theoretical and methodological assumptions preclude direct political analysis, a dichotomy is created in which CDA is constructed as positive and non-critical approaches are constructed as negative. It is important to recognize that non-critical approaches are more than just another option: by refusing to take an opposing stance to established power structures and thus obviating the need for necessary social critique they are either complicit in the reproduction of an unjust social order or aiding in its perpetuation. To analyze CDA critically, we must first understand that the term "critical" is remarkable in and of itself as what has been referred to as "a rhetoric of self-praise" (a rhetoric of self-praise) (Billig 2002, p. 37). It is possible to consider this component of CDA as ideological manipulation, with the goal of undermining the competitors. As Potter (2017) points out, CDA considers criticism to be a natural part of the process.

While this is not always the case, the conclusion appears to be that discourse analysis that is not critical is weak in some way, at least in some cases. In the words of Potter (2017), there is potential for a variety of types of discourse analysis, each of which may or may not result in social criticism, depending on what emerges from the data set. In order to be legitimate, useful, or exciting, discourse analysis does not need to be critical in order to be valid or interesting. Others have argued persuasively that discourse analysis should be recognized as a distinct discipline of language study, particularly in terms of rigorous and impartial standards for analysis and interpretation, and that external concerns such as ideological concerns are not always germane to the enterprise of analysis and interpretation (Antaki et al. 2003).

Critique, on the other hand, is not something that arises or does not emerge from text analysis in the eyes of those working within CDA: it is the very raison d'être of text analysis in the first place.

Billig's evaluation of the situation includes a number of observations that are relevant to our contemporary deliberative situation. To begin with, there is the fundamental canon question to consider. As previously indicated, the philosophical foundation for CDA is a source of disagreement even among those working in the field.

Beginning with a rather explicit neo-Marxist critique of society in the 1980s, the CDA broadened its conceptual horizons to incorporate a wide variety of sociological thinking in the following decades. It is the major emphasis on sociology and individuals with a particular "school" perspective toward late modernity, combined with the use of concepts more broadly associated with post-modern paradigms, that distinguishes CDA as a "approach" or "critical" within the field of language study from the rest of the field. This diverse background appears to have produced a "critical canon" of "radical works of social analysis that conventional linguists never considered to be part of linguistics" (Billig 2002, p. 44), which has been fixed as set texts for the next generation of linguists. In the absence of critical evaluation, this "canon" runs the potential of being accepted without being critically examined, which is concerning, particularly if it contains an imbalance between works on social theory and works on language and linguistic methodologies.

Unrelatedly, CDA's lack of internal reflection and debate tends to reinforce the organization from the outside, as an intellectual paradigm with its own hierarchy and methods of control, but it can detract from the seriousness of its intellectual endeavor. Similarly, Billig (2002) argues that the limited amount of self-criticism that occurs overlooks key features, and he is concerned that the growth in respectability will result in a loss of intellectual originality. To avoid treating CDA as if it 
were a commodity or a brand name for the purpose of labeling one's work in order for it to be published, he asks academics to desist from treating it as if it were such. Critical discourse analysis (without capital letters) is advocated for in order to allow for the formation of new approaches. $\mathrm{He}$ urges scholars to "unpick the rhetoric that has led from 'critical approaches' to the abbreviated and capitalized 'CDA"' (Billig 2002, p. 44). - "Above all, it is vital to encourage fresh academics, particularly those without established positions, to challenge the vocabulary and rhetoric of known critical writers - even to expose the sign'critical"s own self-interest and political economy," he said. As a result, the outcomes would be unpleasant for critical professionals, and they should not be unpleasant if social critique is to continue in the future." 2002, page 45; Billig, 2002, page 45.

\section{Discussion}

I stated in this paper that the relationship between discourse analysis and critique can be viewed in two ways: On the one hand, a critique of certain societal conditions exists and can be carried to a discourse analysis. The critical potential will then largely be determined by the discourse analyst's critical mindset. Due to the fact that critique occurs prior to analysis, it establishes an external relationship with discourse analysis. Thus, I coined the term "discourse analysis and critique" to refer to this interaction. Additionally, I argued that if we view the relationship between discourse analysis and critique in this manner, we will miss the unique critical potential of discourse analysis, precisely because the critique exists independently of the discourse analysis. By contrast, discourse analysis serves as a sort of critique in the sense that it is a discursive construction that generates critical effects that reorganize the regime of sayability. This is demonstrated, for example, in a pivotal statement of this discursive development, namely the assertion that academic activity is inherently interventionist. I next traced the interventionist nature of discourse analysis back to its topic issues, subject relations (including the self-relation), and academic production setting. In the latter, the purported heterogeneity and inconsistency of discourse analysis's theoretical and methodological approaches are critical, since they are a major source of annoyance for mainstream (social) science. As a result of this discomfort, it becomes conceivable to reopen and re-debate the permissible, possible, and helpful scope of academic labor.

\section{Conclusions}

CDA is an interesting paradigm for understanding and evaluating the ways in which ideology acts within and through language, and it is still in its early stages. Because it bridges the gap between natural linguistic phenomena and the social workings of power, it has a distinct advantage over other approaches. A catastrophe would be the failure of this essential mission due to methodological and theoretical deficiencies, which would be unconscionable. To summarize the primary criticisms raised at CDA over the years, as well as to assess their significance for linguists who read CDA practitioners' work or who wish to do research inside the CDA paradigm, we have developed the following tentative findings.

1. Analyzing critical speech is primarily defined by its political purposes, which are discussed further below. When it comes to their political beliefs, most researchers are up forward and honest, at least in general terms. When analyzing their work, it is important to keep these commitments in mind at all times. The field of critical discourse analysis is informed by a diverse range of linguistic and sociological theories.

2. They are not always well defined, and there is a tendency to take concepts from a number of intellectual traditions, not all of which are mutually exclusive. Researchers should make an attempt to clarify the theoretical underpinnings of their work, and readers should feel free to take a critical stance toward the 
theoretical apparatus utilized in CDA studies, or even to call into question the theoretical apparatus's fundamental assumptions.

3. In addition, CDA practitioners have been accused of taking a "impressionistic" approach to text analysis on numerous occasions. Keeping the same level of rigor when dealing with language data as one would in any other area of linguistics is crucial when working with this type of data. One alternative is to employ corpus linguistics techniques in order to generate a more representative overview of a larger sample of linguistic material. Another option is to be less selective and more disciplined and systematic in your text analysis, as opposed to less selective and more selective. Especially when evaluating spoken language, it is important to consider the pragmatic aspect of the situation.

4. In addition, it has been asserted that critical discourse analysts move far too quickly from the step of collecting linguistic data to the stage of interpreting and explaining those data in terms of social theory. If this is the case, readers should proceed with caution when attempting to compare interpretations to available evidence on an impartial basis. In general, in order to produce well-founded interpretations, researchers must show respect for the text itself.

5. The CDA does not provide a thorough enough account of how texts function in social settings. Reader response or audience reception is typically presumed to be positive based on the researcher's opinion of the material, which is frequently incorrect. In order to understand the relationship between texts and subjects, readers need compare and contrast these findings with work in media studies. The CDA community needs to pay greater attention to this component and develop ways for assessing real-world reactions.

6. In addition to expanding their field of vision to include the macrocontext, critical discourse analysts have occasionally neglected features of the immediate context, resulting in interpretations that are either pragmatically unsuitable or distant from the concerns of those who participated. The distinctive peculiarities of the current situation should be taken into consideration by both readers and academics.

7. CDA has spent the last two decades examining how ideology interacts through discourse to maintain unequal power structures. Due to CDA's self-image as a "critical" force, this work has a largely negative tone and appears to promote a deterministic perspective of society, which could be explained by the fact that CDA is a "critical" force. In order to provide insight into the mechanisms through which positive changes in social language usage might be implemented, discourse analysis that investigates emancipatory discourses or positive improvements in social language use would be advantageous.

\section{Competing Interests}

There is no conflict of interest in this work.

\section{References}

[1] Antaki, C., Billig, M., Edwards, D., \& Potter, J. (2003). Discourse analysis means doing analysis: A critique of six analytic shortcomings.. In Discourse Analysis Online, 1, accessed 8 September 2011 at http://www-staff.lboro.ac.uk/ssca1/DAOLpaper.pdf

[2] Baker, P., Gabrielatos, C., Khosravinik, M., Krzyżanowski, M., McEnery, T., \& Wodak, R. (2008). A useful methodological synergy? Combining critical discourse analysis and corpus linguistics to examine discourses of refugees and asylum seekers in the UK press. Discourse \& society, 19(3), 273-306. https://doi.org/10.1177\%2F0957926508088962

[3] V.K. Bhatia (2002) A multi-perspective approach for applied genre analysis. Ibérica 4, no. 3: 319.

[4] Billig, M. (2002) Critical discourse analysis and critique rhetoric. Critical Discourse Analysis: Theory and Interdisciplinarity, edited by G. Weiss and R. Wodak. Palgrave Macmillan, London, pp. 35-46.

[5] Blommaert, J. (2001). Context is/as critique. Critique of anthropology, 21(1), 13-32.

[6] Bluhm, C. Deissler, D. Scharloth, J. \& Stukenbrock, A. (2000) Linguistic Discourse Analysis: Overview, Issues, and Prospects. Language and Literature in Science and Education 88: 3-19.

[7] Bourdieu, P. (1984a) Distinction: A Social Critique of Taste. Routledge, London.

[8] Bourdieu, P. (1984b). Homo Academicus Stanford University Press, Stanford, California. 
[9] Bredehöft, S. Gloy, K. Januschek, F. \& Patzelt R. (2018). To the discursive apprehension of novel life situations. Westdeutscher Verlag, Opladen.

[10] Caldas-Coulthard C. \& Coultard, M. (2017), Texts and Practices: Readings in Critical Discourse Analysis (1996). Routledge, London.

[11] Candlin, C. N., \& Hyland, K. (Eds.). (2014). Writing: Texts, processes and practices. Routledge.

[12] Chouliaraki, L., \& Fairclough, N. (1999). Discourse in late modernity: Rethinking critical discourse analysis (pp. 4-6). Edinburgh: Edinburgh University Press.

[13] Coseriu, E.(1980). Textlinguistik: Eine Einführung,. Narr, Tübingen.

[14] Fairclough, N.(1992a). Discourse and Social Change, Cambridge: Polity,

[15] Fairclough, N. (1992b). Discourse and text: Linguistic and intertextual analysis within the framework of discourse analysis. Discourse \& Society 3.2 (1993-1997): 193-217.

[16] Fairclough, N.(1995). Critical Discourse Analysis,. Longman, London.

[17] Fairclough, N. (1996) A rebuttal to Henry Widdowson's 'Discourse analysis: A critical perspective'. Language and Literature 5.1 (1999): 49-56. A remark

[18] Fairclough, N. (1997) New Labour, a new language? Routledge, London. Reply to Henry Widdowson's 'Discourse analysis: a critical perspective'". N. Fairclough and R. Wodak, Language and Literature 5(1), 49- Analyses of critical discourse. Discourse as Social Interaction, edited by T. van Dijk. 258-284. London: Sage.

[19] Fish, S. (1980) Is This Class Required To Have A Text? Harvard University Press, Cambridge, MA.

[20] Foucault, M.( 1969) The Archaeology of Knowledge, Routledge, London.

[21] Foucault, M. (1981). The Order of Discourse Untying the text: A post-structural anthology, edited by R. Young. Routledge \& Kegan Paul, Boston, pp. 48-78.

[22] Fowler, R. (1991)Language in the News,. Routledge, London.

[23] Fowler, R. (1996)Linguistic Criticism, Oxford University Press,

[24] Fowler, R., Hodge, B., Kress, G. \& Trew. T. (2018) Language and Control. Routledge and Kegan Paul, London.

[25] Gergen, K. (1994). Realities and relationships: Social construction as soundings. Harvard University Press, Cambridge, MA.

[26] Gloy. K.(1998). Ethik-Diskurse. Public Conflict Resolution Practices A summary of a research project. Ethik-Diskurse. Public Conflict Resolution Practices Working Paper No. 1. Universität Oldenburg.

[27] Habermas, J. (1976)Verwissenschaftlichte Politik und öffentliche Meinung, 1976. Technology and Science as 'Ideologies', edited by J. Habermas. Suhrkamp, Frankfurt am Main, pp. 120-45.

[28] Hammersley M. (1997) Critical discourse analysis's underpinnings. Language and Communication, 17(3), pp. 237-248.

[29] Harding, S. (2004). The feminist viewpoint theory reader, edited by S. Harding. Routledge, London

[30] Hodge, R., \& Kress, G. R. (1993). Language as ideology (Vol. 2). London: Routledge.

[31] Hoey, M. (1996) Contrast and congruence in the definitions of man' and 'woman'. Texts and Practices: Readings in Critical Discourse Analysis, edited by C. Caldas-Coulthard and M. Coulthard.Routledge, London, pp. 150-163.

[32] Caldas-Coulthard, C. R., Caldas-Coulthard, C. R., \& Coulthard, M. (1995). Texts and practices. Routledge.

[33] Jäger S.(2017). Kritische Diskursanalyse. A brief introduction. Dissertation, Duisburg.

[34] Kant, Critique of Pure Reason (1781) [1964]. Dent, London.

[35] Kress, G. (1996) Representational resources and the construction of subjectivity in a multicultural society: Issues for the theoretical development of critical discourse analysis. Text and Practices: Readings in Critical Discourse Analysis, edited by C. Caldas-Coulthard and M. Coulthard. Routledge, London, pp. 15-31.

[36] Kuo, S.H. \& Nakamura M. (2005) What is the difference between translation and transformation? Language and ideology in the Taiwanese press: a case study Discourse \& Society 16 , no. 418 , pp. 393-418. 
[37] Luke, A. R. (2003 (2002) Beyond science and ideological critique: Critical discourse analysis's development. Applied Linguistics Annual Review. 22: 96-110.

[38] Macintyre, A.(1981). After Virtue. A work on moral theology. University of Notre Dame Press, South Bend.

[39] Martin, J. (2004) Analysis of positive discourse: Solidarity and change. 179-202 in Revista Canaria de Estudios Ingleses.

[40] Mautner, G. (2001). Checks and balances: How corpus linguistics can help with CDA. Methods of Critical Discourse Analysis, edited by R. Wodak and M. Meyer. Sage, London, pp. 122-143.

[41] Meyer, M. (2001). Between theory, method, and politics: Positioning CDA methods. Methods of critical discourse analysis, edited by R. Wodak and M. Meyer. Sage, London, pp. 14-31.

[42] Nightingale, V. (1996) Audience Research: The Shock of the Real. Routledge, London.

[43] Olson, D. \& Filby, N. (1972). Active and passive sentence comprehension. 3: 361-381. Cognitive Psychology.

[44] Partington, A. (2003). The linguistics of political argument: The spin-doctor and the wolf-pack at the White House. Routledge.

[45] Partington, P. (2006) Corpus assisted discourse studies (CADS) at work: Metaphors, themes, and similes across speech kinds. Corpus-based Approaches to Metaphor and Metonymy, edited by A. Stefanowitsch and S. Gries. Mouton de Gruyter, Berlin, pp. 267-304.

[46] Peace, P. (2003). Balancing power: Women/men at the university's discursive preservation of gender inequity. 159-180 in Feminism and Psychology 13.2.

[47] Pêcheux, M. (2018). Language, Semiotics, and Ideology, 1982. (2nd ed.) Macmillan, London.

[48] Potter, J. (1998) Contextuality of cognition (Whose cognition?). Language and Social Interaction Research 31.1: 29-44

[49] Reese, S. Gandy, O. \& Grant. A.(2003). Media Perspectives and Our Understanding of the Social World. Lawrence Erlbaum Associates, Mahwah, New Jersey.

[50] Reisigl, M.\& Wodak, R.(2001)Discourse and Discrimination,. Routledge, London.

[51] Rogers, R. Malancharuvil-Berkes, E. Mosley, M. Hui, D. \& Joseph G. O'Garro (2005) A survey of the literature on critical discourse analysis in education. Review of Educational Research. 75.3: $365-416$.

[52] Sarangi S. and Roberts, C.(1999) Talk, work, and institutional order: Discourse in medical, institutional, and management settings,. Mouton de Gruyter, Berlin.

[53] Schegloff, E. (1997) Whose text is it? Whose context is this? 165-187 in Discourse and Society 8.2 .

[54] Scholem, G. (2018).Walter Benjamin: The Story of a Friendship, 1982. The New York Review of Books, New York.

[55] Shaw (2019)Reason, nostalgia, and eschatology in Max Horkheimer's critical theory. Journal of Politics, 47.1, pp. 160-181

[56] Slembrouck, S. (2001). Explanation, interpretation, and critique in discourse analysis. 21: 33-57. Critique of Anthropology.

[57] Stenvall, M.(2017). Fear of Terrorism Persists: Fear-mongering in International News Agencies' Terrorism Reports. Discourse, War, and Terrorism, edited by A. Hodges and C. Nilep, Amsterdam: John Benjamins Publishing Company, pp. 205-222.

[58] Stubbs M. (1994) Grammar, text, and ideology all play a role. Computer-assisted methods in representational linguistics. 15.2: 201-223. Applied Linguistics.

[59] Stubbs, M. Whorf's Children: Critical Remarks on Critical Discourse Analysis, 1997. In A. Ryan and A. Wray (eds. ), Evolving language models. Multilingual Matters, Clevedon, pp. 100 116.

[60] Toolan M. (1997) What is critical discourse analysis and why are people so negative about it? Language and Literature 6.2 (2009): 83-102.

[61] Van Dijk, T. (1991). Racism and the media. Routledge, London.

[62] Van Dijk, T.(1993), Elite discourse and racism, Sage, Newbury Park,.

[63] Van Dijk, T. (1999), , Critical discourse analysis and conversation analysis, Discourse and Society 10.4 pp. 459-460.

[64] Van Dijk, T. (2003) What is critical discourse analysis? The handbook of discourse analysis, edited by D. Schiffrin, D. Tannen, and H. Hamilton. Blackwell, Oxford, pp. 352-371. 
[65] Van Dijk, T. (2006),, Discourse and manipulation, Discourse and Society 17.3 pp. 359-383.

[66] Verschueren J. (2001). Criticism's predicaments. 59-81 in Critique of Anthropology 21.1

[67] Wales R.\& Grieve R. (1969) What makes denial so difficult? 6: 327-332. Attention, Perception, and Psychophysics 6.

[68] Weiss G. \& Wodak, R. (2002)Introduction: Theory, Interdisciplinarity, and Critical Discourse Analysis. Theory and Interdisciplinarity, edited by G. Weiss and R. Wodak. Palgrave Macmillan, London, pp. 1-32.

[69] Widdowson, H. (1996) Fairclough's Reply. Interpretation and discourse. Hypotheses and refutations. Language and Literature 5.1. 57-69

[70] Widdowson, H. (1998) Critical Discourse Analysis: Theory and Practice. Applied Linguistics 19.1 (2007): 136-151.

[71] Wodak, R.(1986)Language behavior in therapy groups,. University of California Press, Los Angeles.

[72] Wodak, R. (1996) Discourse disorders. Longman, London.

[73] Wodak, R. (2001). The discourse-historical perspective. In R. Wodak and M. Meyer (eds. ), Critical discourse analysis methods. 63-95. London: Sage.

[74] Wodak, R. (2007) Pragmatics and critical discourse analysis: A multidisciplinary investigation. Pragmatics and Cognitive Science 15.1, pp. 203-225. 